\section{Dispersion of QT and QTc interval in healthy children, and effects of sinus arrhythmia on QT dispersion}

H Ercan Tutar, B Öcal, A Imamoglu, S Atalay
QT interval dispersion is an indirect measure of the heterogeneity of ventricular repolarisation. ${ }^{12}$ A potential application of this interlead difference from standard 12 lead electrocardiograms (ECGs) was first proposed by Day et al in $1990 .{ }^{3}$ Since that time, this concept has been applied to ECGs in various clinical populations ranging from healthy volunteers $^{45}$ to patients with the long QT syndrome,${ }^{6}$ survivors of acute myocardial infarction, ${ }^{7}$ and patients with hypertrophic ${ }^{8}$ and dilated cardiomyopathies, ${ }^{9}$ as well as many other well defined groups. ${ }^{10-12}$ As there are no published data on normal values of QT interval dispersion in the paediatric age group, we planned this study to determine the normal values of QT and QTc dispersion in healthy children.

\section{Methods}

Electrocardiograms were obtained from 372 schoolchildren (200 male, 172 female) seven to 18 years of age (mean (SD):12.4 (2.6) years). Children having acute or chronic illness by either history or physical examination were excluded. The study was approved by the ethics committee of our institution.

Measurements were carried out from standard 12 lead ECGs recorded at a speed of 25 $\mathrm{mm} / \mathrm{s}$ at rest. A three channel electrocardiographic recorder (Hewlett Packard, model 4745 A; Hewlett Packard Inc, Camas, Washington, USA) was used. The QT and preceding $\mathrm{RR}$ intervals of at least one sinus beat (range one to three) were measured in a range of nine to 12 leads, and the mean QT and RR intervals were calculated. The corrected QT interval was calculated by the method of Bazett $(\mathrm{QTc}=\mathrm{QT} /(\mathrm{RR})) .{ }^{13}$ The mean $\mathrm{QT}$ and the mean RR were used to calculate the mean QTc
Keywords: QT dispersion; heart rate; children; sinus arrhythmia
Ankara University Faculty of Medicine, Department of Pediatric Cardiology, Ankara, Turkey

H E Tutar

B Öcal

A Imamoglu

S Atalay

Correspondence to: Dr H Ercan Tutar, Büklüm sokak, 20/17, 06660 Kavaklidere, Ankara, Turkey.

Accepted for publication 16 February 1998
Table 1 Heart rate, RR, QT, and QTc intervals, and QT, QTc, and RR dispersion parameters for normal boys and girls

\begin{tabular}{|c|c|c|c|c|c|c|c|}
\hline & \multicolumn{2}{|c|}{$\begin{array}{l}\text { Boys }(n=200) \text { mean age } 12.3 \\
\text { (2.1) years }\end{array}$} & \multicolumn{2}{|c|}{$\begin{array}{l}\text { Girls }(n=172) \text { mean age } 12.5 \\
\text { (2.3) years }\end{array}$} & \multirow[b]{2}{*}{$p$} & \multicolumn{2}{|c|}{$\begin{array}{l}\text { Whole group }(n=372) \text { mean } \\
\text { age } 12.4(2.6) \text { years }\end{array}$} \\
\hline & Mean (SD) & 95th Centile & Mean (SD) & 95th Centile & & Mean (SD) & 95th Centile \\
\hline HR (beats/min) & $89.1(13.7)$ & 114 & $89.7(13.3)$ & 115 & 0.66 & $89.4(13.6)$ & 114 \\
\hline Mean RR (ms) & $680.3(116.1)$ & 896.1 & $671.9(104.3)$ & 838.6 & 0.47 & $676.9(111.4)$ & 877.7 \\
\hline Mean QT (ms) & $324.3(22.6)$ & 360.9 & $328.4(26.1)$ & 366.1 & 0.10 & $325.9(24.1)$ & 363.7 \\
\hline Mean QTc (ms) & $396.1(20.2)$ & 432.2 & $402.6(18.2)$ & 432.8 & 0.001 & $398.7(19.7)$ & 432.4 \\
\hline QT max (ms) & $339.2(23.2)$ & 380 & $343.4(27.7)$ & 390 & 0.11 & $340.8(25.2)$ & 380 \\
\hline QTc max (ms) & $420.7(23.4)$ & 453.5 & $425.8(18.8)$ & 462 & 0.026 & $422.7(21.8)$ & 457.6 \\
\hline QTD (ms) & $29.8(9.8)$ & 50 & $30.0(10.9)$ & 50 & 0.90 & $29.9(10.2)$ & 50 \\
\hline QTcD (ms) & $47.9(16.9)$ & 80.4 & $46.5(16.2)$ & 75 & 0.42 & $47.3(16.6)$ & 79.7 \\
\hline QT-SD (ms) & $9.7(3.1)$ & 15.5 & $10.0(3.3)$ & 16.3 & 0.41 & $9.8(3.2)$ & 15.6 \\
\hline QTc-SD (ms) & $15.5(5.6)$ & 27.0 & $15.4(5.5)$ & 26.4 & 0.93 & $15.5(5.5)$ & 26.9 \\
\hline RRD (ms) & $96.9(70.3)$ & 274 & $89.8(64.4)$ & 320 & 0.32 & $94.1(68.0)$ & 250 \\
\hline RR-SD (ms) & $39.8(29.4)$ & 107.4 & $36.8(26.5)$ & 93.7 & 0.31 & $38.6(28.3)$ & 101.5 \\
\hline
\end{tabular}

HR, heart rate. 
Table 2 Correlations of QT and QTc dispersion parameters with age and other ECG measurements

\begin{tabular}{|c|c|c|c|c|c|c|c|c|c|}
\hline & Mean $Q T$ & Mean Qtc & $Q T D$ & $Q T c D$ & $Q T-S D$ & $Q T c-S D$ & $R R D$ & $R R-S D$ & Age \\
\hline Mean RR & $0.78(<0.001)$ & -0.43 & -0.06 & -0.12 & -0.06 & -0.15 & $0.52(<0.001)$ & $0.55(<0.001)$ & -0.37 \\
\hline Mean QT & & 0.20 & 0.12 & 0.11 & 0.12 & 0.13 & 0.36 & 0.35 & 0.46 \\
\hline Mean QTc & & & 0.06 & -0.0005 & 0.09 & -0.01 & -0.32 & -0.32 & 0.06 \\
\hline QTD & & & & $0.52(<0.001)$ & $0.89(<0.001)$ & 0.44 & 0.08 & 0.09 & 0.04 \\
\hline QTcD & & & & & $0.53(<0.001)$ & $0.93(<0.001)$ & $0.51(<0.001)$ & $0.51(<0.001)$ & 0.01 \\
\hline QT-SD & & & & & & 0.49 & 0.09 & 0.09 & 0.05 \\
\hline QTc-SD & & & & & & & $0.58(<0.001)$ & $0.59(<0.001)$ & 0.03 \\
\hline RRD & & & & & & & & $0.99(<0.001)$ & 0.13 \\
\hline RR-SD & & & & & & & & & 0.13 \\
\hline
\end{tabular}

$r$ Values are presented as Pearson's correlation coefficients. Numbers in parentheses are p values.

for each lead. Heart rate was derived from the mean of the RR intervals. The QT and RR intervals were measured manually with calipers by a single observer. Repeatability of the QT and QTc measurements was tested by a second observer, who measured the same intervals of lead II in 50 randomly selected electrocardiograms. QT intervals were measured from the onset of the QRS complex to the end of the T wave. The end of the $T$ wave was defined as the point of return to the isoelectric line. When a $U$ wave was present, the QT interval was measured to the nadir of the curve between the $\mathrm{T}$ and $\mathrm{U}$ wave. ${ }^{10}$

Dispersion of the QT and QTc were defined in two ways: (1) the difference between the maximum and minimum QT and QTc intervals occurring in any of the 12 leads (QTD, QTCD), and (2) the standard deviation of the QT and QTc interval in the leads that could be measured (QT-SD, QTc-SD). ${ }^{14}$ RR variation was also calculated in a same manner (RRD and RR-SD, respectively). Sinus arrhythmia was defined as RRD of $\geqslant 80 \mathrm{~ms}$, without significant change in $\mathrm{P}$ wave or frontal plane axis. $^{15}$

All data are expressed as mean (SD). Paired and unpaired Student's $t$ tests were used where appropriate. Correlations were assessed by Pearson's coefficients. A two tailed $\mathrm{p}$ value $<0.05$ was considered significant.

\section{Results}

All analyses were done by sex, age, heart rate, and the presence of sinus arrhythmia. Heart rate and ECG data of normal children are shown in table 1 . The QT intervals were similar for boys and girls. Both the mean and the 95th centile QTc intervals were significantly greater for girls than for boys. There was no significant difference in QT, QTc, and RR dispersion parameters between boys and girls. We found that neither QT nor QTc dispersion parameters were correlated with age. There

Table 3 ECG parameters in children with and without sinus arrhythmia

\begin{tabular}{lccc}
\hline & $\begin{array}{l}S A(+) \\
(n=198) \\
\text { mean }(S D)\end{array}$ & $\begin{array}{l}S A(-) \\
(n=174) \\
\text { mean }(S D)\end{array}$ & p value \\
\hline Age (years) & $12.7(2.5)$ & $12.1(2.7)$ & $<0.05$ \\
Mean RR (ms) & $726.3(103.0)$ & $620.7(92.6)$ & $<0.001$ \\
Mean QT (ms) & $334.0(22.0)$ & $316.8(23.2)$ & $<0.001$ \\
Mean QTc (ms) & $394.3(19.8)$ & $403.7(18.3)$ & $<0.001$ \\
QTD (ms) & $30.6(10.3)$ & $29.1(10.0)$ & 0.14 \\
QTcD (ms) & $52.9(17.4)$ & $40.9(13.1)$ & $<0.001$ \\
QT-SD (ms) & $10.1(3.3)$ & $9.5(2.9)$ & 0.07 \\
QTc-SD (ms) & $17.5(5.9)$ & $13.2(4.0)$ & $<0.001$ \\
\hline SA (+), presen & & &
\end{tabular}

SA (+), presence; SA (-), absence of sinus arrhythmia. was a significant positive correlation between RR and QT intervals $(r=0.78)$. We found that QTD and QT-SD did not vary significantly with RR, RRD, or RR-SD, but both QTcD and QTc-SD varied significantly with RRD and RR-SD (table 2). Sinus arrhythmia was present in 198 children (53\%). QTD and QT-SD were not affected by sinus arrhythmia, but both QTcD and QTc-SD were significantly greater in children with sinus arrhythmia than those without (table 3).

In the 50 selected ECGs, the mean of QT intervals measured, and the mean of QTc intervals calculated, were similar between observer 1 and observer 2 (QT: 334.6 (26.1) ms v $335.6(23.8) \mathrm{ms}, \mathrm{p}=0.5, r=0.92$; QTc: 391.9 (25.4) ms v 393.7 (27.7) $\mathrm{ms}, \mathrm{p}=0.31$, $r=0.90)$.

\section{Discussion}

In a large normal adult population $(\mathrm{n}=1555)$, Macfarlane et al showed that the upper limit of QT dispersion using an automated method was $40 \mathrm{~ms} .{ }^{16}$ In addition, data for matched controls in most studies including adults suggest that QTD and QTcD in normal subjects are usually in the range of $30-50 \mathrm{~ms}$ and $40-60 \mathrm{~ms}$, respectively ${ }^{4-691012}$ As far as is known, there are no published limits of normal QT interval dispersion in the paediatric age group, and it is possible that the data in our study are the first in which such results are presented. QT interval dispersion results of our population study, which included a relatively large number of children, are correlated with adults results. Dispersion of QT and QTc intervals were found to be 29.9 (10.2) $\mathrm{ms}$ and 47.3 (16.6) $\mathrm{ms}$, respectively. We also used standard deviation of QT, QTc, and RR intervals as a measure of dispersion, to minimise probable errors resulting from non-measurable leads. We found that QT-SD, QTc-SD, and RR-SD correlated significantly with the corresponding values of QTD, QTcD, and RRD.

In a recent study, Pearl showed that QTc intervals were significantly greater for girls than for boys in the 14 to 18 year age range. ${ }^{17} \mathrm{We}$ also showed this sex difference in our study group.

In a small number of healthy adult subjects $(\mathrm{n}=25)$, Fei et al showed that the difference in the QT dispersion between men and women was significant. ${ }^{4}$ However, we did not find that sex had a significant impact on QT or QTc dispersion parameters in children. Macfarlane et al also showed that there was no difference between men and women for QT interval dispersion. ${ }^{16}$ In our study, age and heart rate 
were not found to have an effect on QT and QTc dispersion in children either.

Nearly half of the children in our study group had sinus arrhythmia. We therefore determined whether sinus arrhythmia had an effect on QT and QTc dispersion in children. Although QT dispersion parameters (QTD and QT-SD) did not vary significantly with $R R$ variation (for example, with $R R D$ and RR$\mathrm{SD}$ ), we observed that QTc dispersion parameters did vary significantly with RR dispersion. As a result, children with sinus arrhythmia not surprisingly have greater QTcD and QTc-SD values than children without sinus arrhythmia. Indeed, Anderson showed that despite a large variation in $R R$ interval, the $Q T$ interval remained relatively stable in sinus arrhythmia, and QTc consequently showed considerable beat to beat variation. ${ }^{18}$ Fei et al also found that there was no significant relation between QT dispersion and $R R$ variation in patients with congestive heart failure. ${ }^{19}$

We have not been able to analyse the beats all through the respiratory cycle and this is the limitation of our results. We might have found a smaller variation in QTc in children with sinus arrhythmia if we had been able to analyse the beats in this way.

In conclusion, as QT interval changes are not correlated significantly with beat to beat RR variation, the computation of QTc dispersion is seriously affected by the presence or absence of sinus arrhythmia if simultaneous 12 lead ECG recordings are not used. Thus we suggest that, since sinus arrhythmia is a common condition in childhood, QT dispersion should not be corrected for heart rate in children.

1 Day CP, McComb JM, Campbell RWF. QT dispersion in sinus beats and ventricular extrasystoles in normal hearts. Br Heart $\mathcal{F} 1992 ; 67: 39-41$.
2 Zabel M, Portnoy S, Franz MR. Electrocardiographic indexes of dispersion of ventricular repolarization: an isolated heart validation study. $\mathcal{F}$ Am Coll Cardiol 1995;25 746-52.

3 Day CP, McComb JM, Campbell RWF. QT dispersion: an indication of arrhythmia risk in patients with long QT intervals. Br Heart 7 1990;63:342-4.

4 Fei L, Statters DJ, Camm AJ. OT-interval dispersion on 12-lead electrocardiogram in normal subjects: its reproducibility and relation to the $\mathrm{T}$ wave. Am Heart $\mathcal{f}$ 1994;127:1654-5.

5 Kautzner J, Yi G, Camm AJ, et al. Short and long term reproducibility of QT, QTc, and QT dispersion measurement in healthy subjects. Pace 1994;17:928-37.

6 Linker NJ, Colonna P, Kekwick CA, et al. Assessment of QT dispersion in symptomatic patients with congenital long QT syndromes. Am 7 Cardiol 1992;69:634-8.

7 Zareba W, Moss AJ, leCessie S. Dispersion of ventricular repolarization and arrhythmic death in coronary artery disease. Am f Cardiol 1994;74:550-3.

8 Buja G, Miorelli M, Turrini P, et al. Comparison of QT dispersion in hypertrophic cardiomyopathy between patients with and without ventricular arrhythmias and sudden death. Am f Cardiol 1993;72:973-6.

9 Grimm W, Steder U, Menz V, et al. QT dispersion and arrhythmic events in idiopathic dilated cardiomyopathy. Am 7 Cardiol 1996;78:458-61.

10 Barr CS, Naas A, Freeman M, et al. QT dispersion and sudden unexpected death in chronic heart failure. Lancet 1994;343:327-9.

11 Daliento L, Caneve F, Turrini P, et al. Clinical significance of high-frequency, low-amplitude electrocardiographic signals and QT dispersion in patients operated on tetralogy of Fallot. Am f Cardiol 1995;76:408-411.

12 Durakovic Z, Durakovic A, Korsic M. Changes of the corrected Q-T interval in the electrocardiogram of patients with anorexia nervosa. Int 7 Cardiol 1994;45:115-20.

13 Bazett JC. An analysis of time relations of electrocardiograms. Heart 1920;7:353-67.

14 Statters DJ, Malik M, Ward DE, et al. QT dispersion: problems of methodology and clinical significance. $\mathcal{F}$ Cardiovasc Electrophysiol 1994;5:672-85.

15 Martin AB, Perry JC, Robinson JL, et al. Calculation of QTc duration and variability in the presence of sinus arrhythmia. Am 7 Cardiol 1995; 75:950-2

16 Macfarlane PW, McLaughlin SC, Yang TF. Effects of age, sex, and race on ECG interval measurements. F Electrocardiol 1994;27(suppl):14-19.

7 Pearl W. Effects of gender, age, and heart rate on QT intervals in children. Pediatr Cardiol 1996;17:135-6.

18 Anderson RC. Q-T interval in sinus arrhythmia. $f$ Electrocardiol 1981;14:407-8.

19 Fei L, Goldman JH, Prasad K, et al. QT dispersion and RR variations on 12-lead ECGs in patients with congestive heart failure secondary to idiopathic dilated cardiomyopathy. Eur Heart $\mathcal{F} 1996 ; 17: 258-63$. 